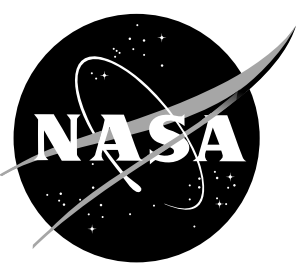

\title{
Development and Testing of a High Stability Engine Control (HISTEC) System
}

John S. Orme

Dryden Flight Research Center

Edwards, California

John C. DeLaat

NASA Lewis Research Center

Cleveland, Ohio

Robert D. Southwick and George W. Gallops

United Technologies Corporation

Pratt \& Whitney

West Palm Beach, Florida

Paul M. Doane

Boeing Phantom Works

St. Louis, Missouri 


\section{The NASA STI Program Office . . . in Profile}

Since its founding, NASA has been dedicated to the advancement of aeronautics and space science. The NASA Scientific and Technical Information (STI) Program Office plays a key part in helping NASA maintain this important role.

The NASA STI Program Office is operated by Langley Research Center, the lead center for NASA's scientific and technical information. The NASA STI Program Office provides access to the NASA STI Database, the largest collection of aeronautical and space science STI in the world. The Program Office is also NASA's institutional mechanism for disseminating the results of its research and development activities. These results are published by NASA in the NASA STI Report Series, which includes the following report types:

- TECHNICAL PUBLICATION. Reports of completed research or a major significant phase of research that present the results of NASA programs and include extensive data or theoretical analysis. Includes compilations of significant scientific and technical data and information deemed to be of continuing reference value. NASA's counterpart of peer-reviewed formal professional papers but has less stringent limitations on manuscript length and extent of graphic presentations.

- $\quad$ TECHNICAL MEMORANDUM. Scientific and technical findings that are preliminary or of specialized interest, e.g., quick release reports, working papers, and bibliographies that contain minimal annotation. Does not contain extensive analysis.

- CONTRACTOR REPORT. Scientific and technical findings by NASA-sponsored contractors and grantees.
- CONFERENCE PUBLICATION.

Collected papers from scientific and technical conferences, symposia, seminars, or other meetings sponsored or cosponsored by NASA.

- SPECIAL PUBLICATION. Scientific, technical, or historical information from NASA programs, projects, and mission, often concerned with subjects having substantial public interest.

- TECHNICAL TRANSLATION. Englishlanguage translations of foreign scientific and technical material pertinent to NASA's mission.

Specialized services that complement the STI Program Office's diverse offerings include creating custom thesauri, building customized databases, organizing and publishing research results ... even providing videos.

For more information about the NASA STI Program Office, see the following:

- Access the NASA STI Program Home Page at http://www.sti.nasa.gov

- E-mail your question via the Internet to help@sti.nasa.gov

- Fax your question to the NASA Access Help Desk at (301) 621-0134

- Telephone the NASA Access Help Desk at (301) 621-0390

- Write to:

NASA Access Help Desk

NASA Center for AeroSpace Information 7121 Standard Drive

Hanover, MD 21076-1320 


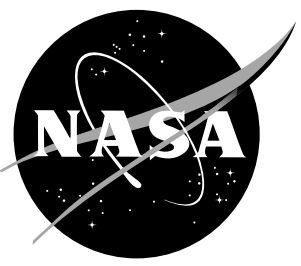

\section{Development and Testing of a High Stability Engine Control (HISTEC) System}

John S. Orme

Dryden Flight Research Center

Edwards, California

John C. DeLaat

NASA Lewis Research Center

Cleveland, Ohio

Robert D. Southwick and George W. Gallops

United Technologies Corporation

Pratt \& Whitney

West Palm Beach, Florida

Paul M. Doane

Boeing Phantom Works

St. Louis, Missouri

National Aeronautics and

Space Administration

Dryden Flight Research Center

Edwards, California 93523-0273 


\section{NOTICE}

Use of trade names or names of manufacturers in this document does not constitute an official endorsement of such products or manufacturers, either expressed or implied, by the National Aeronautics and Space Administration.

Available from the following:

NASA Center for AeroSpace Information (CASI)

7121 Standard Drive

Hanover, MD 21076-1320

(301) 621-0390
National Technical Information Service (NTIS)

5285 Port Royal Road

Springfield, VA 22161-2171

(703) $487-4650$ 


\title{
DEVELOPMENT AND TESTING OF A HIGH STABILITY ENGINE CONTROL (HISTEC) SYSTEM
}

\author{
John S. Orme* \\ NASA Dryden Flight Research Center \\ Edwards, California \\ John C. DeLaat ${ }^{\dagger}$ \\ NASA Lewis Research Center \\ Cleveland, Ohio \\ Robert D. Southwick ${ }^{\ddagger}$ and George W. Gallops ${ }^{\S}$ \\ United Technologies Corporation \\ Pratt \& Whitney \\ West Palm Beach, Florida \\ Paul M. Doane $e^{\text {II }}$ \\ Boeing Phantom Works \\ St. Louis, Missouri
}

\begin{abstract}
$\underline{\text { Abstract }}$
Flight tests were recently completed to demonstrate an inlet-distortion-tolerant engine control system. These flight tests were part of NASA's High Stability Engine Control (HISTEC) program. The objective of the HISTEC program was to design, develop, and flight demonstrate an advanced integrated engine control system that uses measurement-based, real-time estimates of inlet airflow distortion to enhance engine stability. With improved stability and tolerance of inlet airflow distortion, future engine designs may benefit from a reduction in design stall-margin requirements and enhanced reliability, with a corresponding increase in performance and decrease in fuel consumption. This paper describes the HISTEC methodology, presents an aircraft test bed description (including HISTEC-specific modifications) and verification and validation ground tests. Additionally, flight test safety considerations, test plan and technique design and approach, and flight operations are addressed. Some illustrative results are presented to demonstrate the type of analysis and results produced from the flight test program.

\footnotetext{
*Aerospace Engineer, AIAA member no. 102066-00.

Control Systems Engineer, AIAA member.

*Project Engineer.

$\S_{\text {Technology Manager, ASME member. }}$

$\mathbb{I}_{\text {Engineering Manager. }}$

Copyright (C) 1998 by the American Institute of Aeronautics and
} Astronautics, Inc. No copyright is asserted in the United States under Title 17, U.S. Code. The U.S. Government has a royalty-free license to exercise all rights under the copyright claimed herein for Governmental purposes. All other rights are reserved by the copyright owner.
\end{abstract}

\section{Nomenclature}

ACTIVE Advanced Control Technology for
Integrated Vehicles

ADC airdata computer

AOA angle of attack, deg

AOSS angle of sideslip, deg

BPW Boeing Phantom Works, St. Louis, Missouri

CC central computer

CST combined systems test

DES distortion estimation system

DFRC Dryden Flight Research Center, Edwards, California

EAIC electronic air inlet control computer

EMC electromagnetic compatibility

FCS flight control system

$g \quad$ acceleration of gravity

HIDEC F-15 Highly Digital Electronic Engine Control

HILS hardware-in-the-loop-simulation

HISTEC High Stability Engine Control

ID inner diameter

IDEEC improved digital electronic engine control 


$\begin{array}{ll}\text { IFPC } & \text { integrated flight and propulsion control } \\ \text { KCAS } & \text { calibrated airspeed, kn } \\ \text { MUX } & \text { Military Standard } 1553 \text { multiplex data bus } \\ \text { NC } & \text { nozzle control computer } \\ \text { OD } & \text { outer diameter } \\ \text { PCM } & \text { pulse code modulation } \\ \text { Psf } & \text { pounds per square foot, lb/ft }{ }^{2} \\ \text { PW } & \text { Pratt \& Whitney } \\ \text { SIT } & \text { software integration test } \\ \text { SMC } & \text { stability management control law } \\ \text { S/MTD } & \text { Short Take-Off and Landing/Maneuver } \\ & \text { Technology Demonstrator } \\ \text { VMSC } & \text { vehicle management system computer } \\ & \text { Introduction }\end{array}$

Integrated propulsion controls technology has been successfully demonstrated on several previous flight test programs to provide propulsion system stability and performance enhancements. Traditionally, it has been the standard practice to design propulsion system control schedules to accommodate worst-case stability conditions at all times, even though worst case conditions were rarely encountered. Because there was no means of determining the variability of stability margins in real-time, control schedules were not optimized for peak performance, but rather for maintaining an excess buffer of stability margin. This worst-case stability margin buffer usually resulted in reduced performance. Digital engine, inlet and flight control, and communications have allowed for improved integrated propulsion control techniques to recapture some of that lost performance. ${ }^{1}$ For example, with shared digital information, real-time stability margin identification may be used with adaptive control techniques to optimize propulsion system performance, or conversely, improve the robustness of the controller in response to instabilities.

High levels of inlet airflow distortion can lead to propulsion system instabilities such as engine stall or surge. On the F-15 that has variable geometry inlets, an inlet control is designed about the airflow demands of the engine. Meanwhile, a separate engine control is designed to accommodate the worst levels of distortion with sufficient stability margin to ensure stall-free engine operation. But because the subsystems were not designed to communicate in flight, performance compromises were unavoidable. The F-15 Highly Integrated Digital Electronic Engine Control (HIDEC) program addressed these shortcomings in a series of flight test experiments to demonstrate the benefits of integrated controls. Distortion effects on engine stability were directly modeled onboard with airdata inputs to preprogrammed engine control schedules. The HIDECunique engine control then determined whether excessive margins existed for the purposes of increasing performance. Indeed, HIDEC showed performance improvements such as thrust increases, fuel consumption reductions, and cooler turbine temperatures. $^{2}$

A new technique for estimating inlet distortion and its effects on engine stability has been developed as part of the NASA High Stability Engine Control (HISTEC) program. ${ }^{3}$ Distortion estimation is accomplished with a limited number of high-response static pressure measurements at the engine face and a frequency-based reduction algorithm. The algorithm, known as the distortion estimation system (DES), predicts the loss of engine stability margin as a result of inlet distortion. ${ }^{3}$ The DES relies on measurements that are more closely correlated to distortion than the HIDEC model-based approach. An online stability audit technique, similar to that developed for HIDEC, was combined with the DES to form the basis of a stability management control law (SMC). Unlike the HIDEC approach of up-matching the engine for improved performance at low distortion levels, the new SMC is designed to operate with improved performance schedules closer to stall. For high distortion levels, the SMC will down-match the engine as required to maintain system stability. The resulting reduction in design stall margin requirements can influence new engine design for improved performance or reduced weight, or both.

The overall goal of the HISTEC program is to define the requirements for, design, develop, and demonstrate in flight an advanced high stability engine control system that uses real-time estimation of distortion to enhance engine stability. The HISTEC program consists of three phases: Phase I Algorithm Development, Phase II System Development, and Phase III Engine Test/Flight Demonstration. The flight test demonstration of the HISTEC distortion-tolerant control system was conducted at the NASA Dryden Flight Research Center (DFRC), Edwards, California during the summer months of 1997 on the F-15 ACTIVE (Advanced Control Technology for Integrated Vehicles) research aircraft. Specific flight test objectives were to calibrate and verify the DES and stability accommodation. ${ }^{4}$ 
A low-cost, minimal-impact-to-schedule philosophy was adopted for implementing HISTEC systems with the F-15 ACTIVE vehicle. Aircraft modifications to accommodate the HISTEC systems primarily involved the right-hand engine, integration of a research computer, and a new instrumentation system. To minimize the impact of adding a new research computer, the HISTEC research computer was integrated with the existing aircraft avionics by replacing an existing ACTIVE research computer. This approach eliminated the need for any flight control software changes to ACTIVE. To accommodate the additional sensors and measurement recording requirements for HISTEC, a new instrumentation system was added to the aircraft.

The HISTEC program is managed by NASA Lewis Research Center, Cleveland, Ohio. The prime contractor for the program is Pratt \& Whitney (PW), a division of United Technologies, West Palm Beach, Florida. NASA's Dryden Flight Research Center managed flight testing activities. Boeing Phantom Works (BPW), (formerly McDonnell Douglas) St. Louis, Missouri, assisted in the integration of the HISTEC systems onto the aircraft. The U.S. Air Force provided the airframe, engine, and related systems. Flight tests have augmented existing databases for inlet distortion data, validated the distortion estimation method, and confirmed the ability of the HISTEC distortion-tolerant control to accommodate time-varying distortion. ${ }^{5}$ This paper documents the preparation and execution of the HISTEC flight test, including aircraft modifications and verifications of those changes, flight test plan and development of flight test techniques, safety considerations, and flight operations. Use of trade names or names of manufacturers in this document does not constitute an official endorsement of such products or manufacturers, either expressed or implied, by the National Aeronautics and Space Administration.

\section{HISTEC Algorithm Description}

The distortion-tolerant control approach developed for HISTEC is illustrated in Figure 1. The approach uses a distortion-sensing concept developed by PW and a practical design implementation for estimating in-flight distortion. The DES is integrated with advanced stability management control laws designed for the F100-PW-229 improved digital electronic engine control (IDEEC). High-response pressure measurements at the engine face are used as inputs to the DES. For the HISTEC flight test, the DES computer calculates realtime inlet distortion characteristics from fan inlet pressure measurements. The DES then determines corresponding engine stall line sensitivities for the sensed distortion. The DES also uses data from the aircraft flight control system to predict high angle of attack (AOA) and angle of sideslip (AOSS) conditions. This look-ahead capability allows the HISTEC

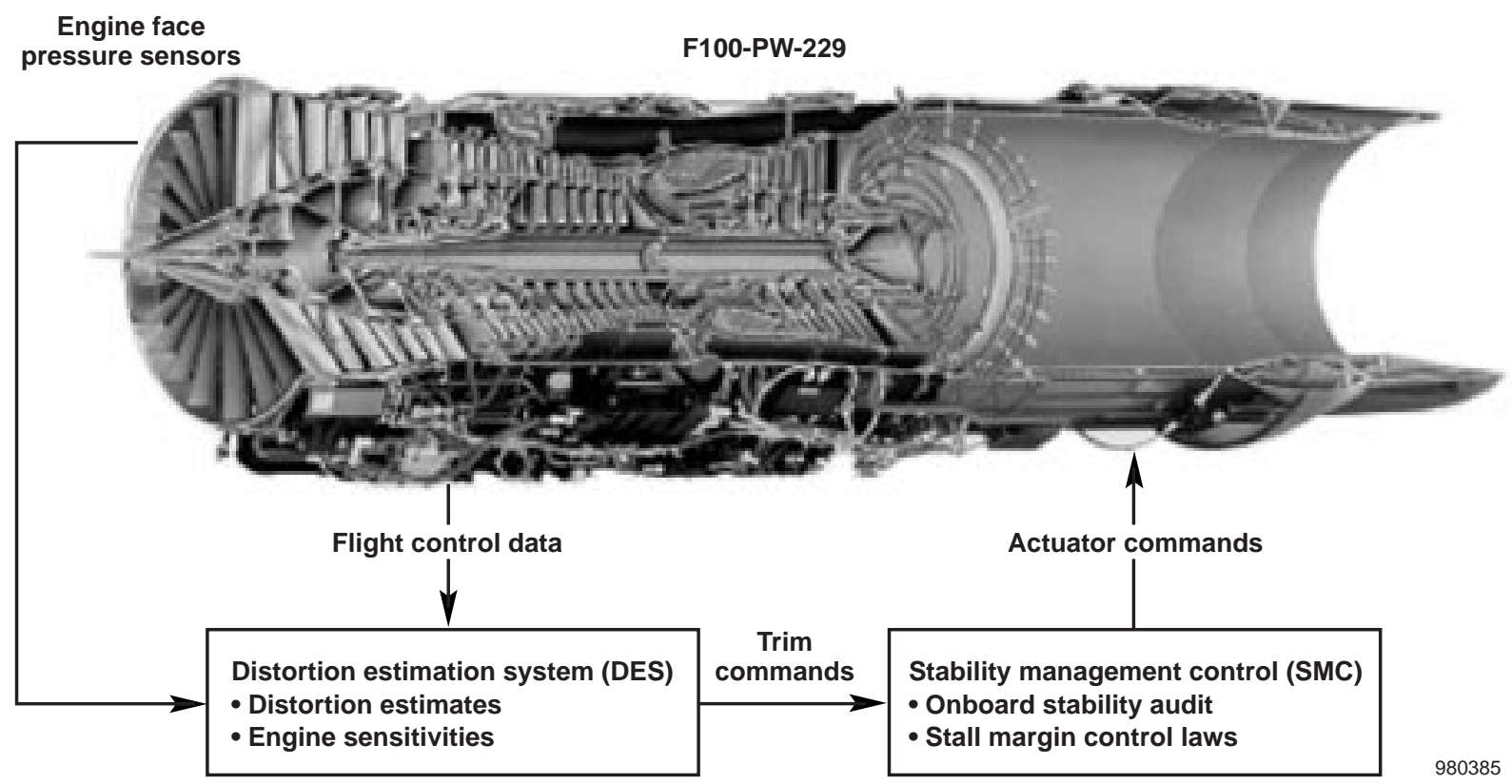

Figure 1. HISTEC approach. 
controller to anticipate and accommodate for high distortion conditions in a timely fashion. The primary outputs of the DES are commands to the IDEEC that trim the fan and compressor operating lines.

To implement HISTEC, advanced control laws were added to the IDEEC for managing the fan and compressor transient operating lines. An onboard realtime stability audit of all destabilizing factors for the fan and compressor was added to the engine controller. The capability for improving engine stability under all conditions, including high levels of distortion, is achieved by including measurement-based distortion effects in the onboard stability audit, and operating the engine with stability management control laws.

\section{$\underline{\text { Aircraft Description }}$}

The aircraft used in the HISTEC program is a highly modified preproduction, two-seat F-15B (fig. 2) referred to as the ACTIVE aircraft. This aircraft is controlled by a quad-redundant, full authority digital fly-by-wire flight control system (FCS), coupled canards, a glass cockpit similar to the F-15E cockpit, and sophisticated onboard computers for evaluating advanced aircraft and engine control algorithms. All mechanical linkages between the control stick, rudder pedals, and control surfaces have been removed from the aircraft. The throttles control the engines digitially through the FCS, and no mechanical linkages exist between the throttles and the engines. Ten major separate computers form
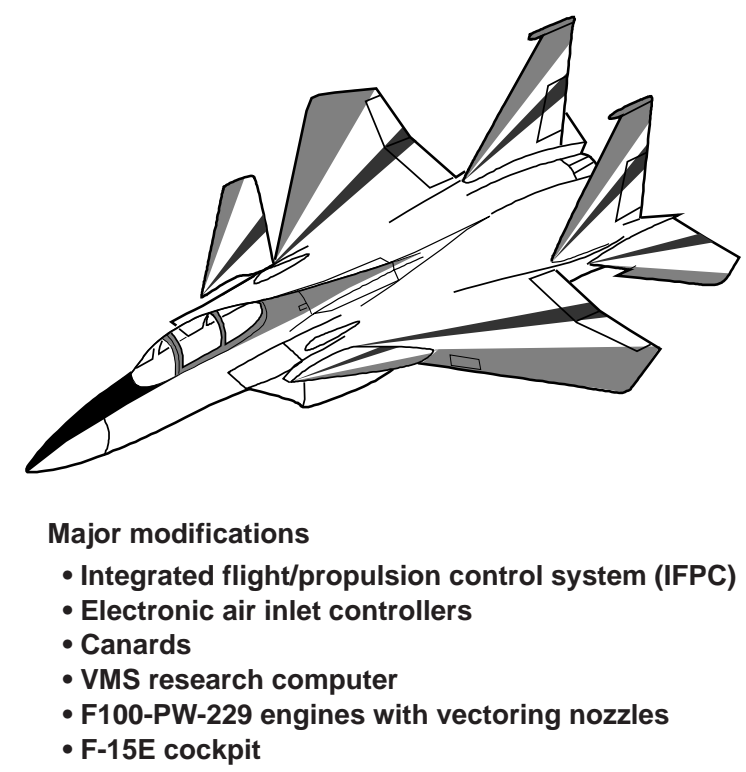

980386

Figure 2. F-15 ACTIVE test bed.
ACTIVE's highly integrated flight and propulsion control (IFPC) system. These computers are linked using the MIL-STD-1553 multiplex data bus (MUX).

The ACTIVE propulsion system consists of two F100-PW-229 engines, each of which is equipped with a PW axisymmetric thrust vectoring nozzle. An engine mounted IDEEC and avionics bay-mounted nozzle control computer (NC) provide closed-loop control of each respective component. However, the nozzle vectoring system was depowered and never engaged during any HISTEC flight mission.

The F100-PW-229 is the most recent production model in the F100 series of engines. It is an augmented 29,000 lbf thrust class motor, featuring a three-stage fan and ten-stage compressor, each driven by a two-stage turbine. An eleven-segment augmentor delivers smooth afterburner ignition and transient performance.

The ACTIVE aircraft (fig. 2), like other F-15 aircraft, has two two-dimensional, three-ramp, external compression inlets which supply airflow to the engines. For supersonic operation, compression is accomplished through three oblique shocks and one terminal normal shock. The aircraft has two electronic air inlet controllers to control the inlet variable geometry. The inlet control logic configures the inlet to achieve adequate performance while maintaining safe operating margins. An inlet delivers high performance when it provides for high pressure recovery at the engine face and low airflow spillage drag. The inlet controller maintains inlet stability margins by using schedules to avoid encountering inlet buzz and supercritical operation. Inlet buzz is primarily a high distortion phenomena that occurs at low airflows. Supercritical operation occurs when the oblique shocks terminate inside of the inlet lip, and the normal shock is ingested beyond the inlet throat. Additional information on this test vehicle and its vectoring nozzles can be found in references 6 and 7 .

\section{Aircraft Modifications for HISTEC}

Extensive modifications were made to the ACTIVE aircraft to accommodate the HISTEC system. The most significant changes involved the right-hand engine, a new instrumentation system, and a new research computer. The right-hand F100-PW-229 engine was fitted with a highly instrumented inlet case for flight testing. A third instrumentation system was added to the ACTIVE to measure and record the required parameters. A new research computer hosting the DES algorithm required avionics integration. 


\section{Engine Modifications}

The DES algorithm required only 6 high-response inlet static pressure inputs: 5 outer diameter (OD) wall static sensors mounted circumferentially around the inlet and the average of 5 inner diameter (ID) wall static sensors. In addition to the HISTEC system static pressures, separate instrumentation to measure temperature and pressure were incorporated into an engine inlet case. The instrumented inlet case is a Bill-of-Material F100-PW-229 inlet case, modified to install 35 strut leading-edge total pressure sensors, 7 strut leading-edge total temperature sensors, 9 OD and 5 ID high-response static pressure sensors. The strut leading-edge pressure sensors are located on 7 struts, 5 sensors per strut, distributed radially by equal flowpath area. These pressure sensors served as an independent reference for evaluating the DES. The total temperature sensors are located at approximately midspan on the same inlet struts as the total pressure sensors. Static pressure taps are located between struts on the OD and ID inlet case shrouds. An aircraft-mounted electrical signal averaging circuit was required to provide an average of the five I.D. signals to the DES computer.

Hardware modifications external to the engine were required to accommodate HISTEC inlet instrumentation installation. Minor modifications to the engine externals were made to prevent physical interference. Anti-ice capability was removed to prevent high temperatures from damaging the inlet strut flight test instrumentation. Removal of the engine anti-ice air supply manifold and valve, which is between the engine bleed air supply and inlet case, provided the necessary room for inlet sensor lead wire routing and termination.

No hardware modifications were required for the IDEEC. The production engine control software was modified to incorporate the stability management features of HISTEC. This software was implemented within the existing engine control laws. The IDEEC software is designed to allow easy updates on the flightline to engine control schedules and constants.

\section{Distortion Estimation System Computer}

For HISTEC, an F119 comprehensive engine diagnostic unit was used as the DES computer. This computer was selected for its computational capability, availability, and flight-quality design. To reduce cost, the unit was aircraft mounted and required no environmental conditioning. The DES computer is connected to the avionics MUX in place of the Channel-B vehicle management system computer
(VMSC) and is required to emulate a portion of the VMSC bus traffic. The DES receives airframe and engine control inputs through the MUX. The message traffic (i.e. size and number of messages) is set to be consistent with the existing aircraft flight test data communications architecture. A digital signal processor in the DES executed all of the distortion estimation algorithms that were programmed in the Ada software language. The DES hardware and software were designed to facilitate flight-line software updates to the DES constants and schedules.

The main inputs to the DES computer are 6 inlet pressures (5 OD wall static sensors and the average of the 5 ID wall static sensors); aircraft altitude and Mach number; and engine low rotor speed, high rotor speed, inlet temperature and airflow. Other airframerequired inputs are used to support the VMSC emulation and an AOA/AOSS predictor algorithm supplied by BPW. The outputs are (1) the distortion related trims to the fan and compressor stall pressure ratio and (2) the inlet face average pressure.

Another algorithm predicted the aircraft's AOA and AOSS one-half second in the future. Inputs to this predictor algorithm included AOA from the airdata computer (ADC), pilot stick and pedal positions, and aircraft lateral acceleration. This algorithm allowed the DES to downmatch the engine prior to dynamic aircraft maneuvering, allowing the engine control to provide the necessary stall margins to accommodate the anticipated high distortion flight conditions.

\section{Avionics Modifications and Integration}

The IFPC avionics architecture of the ACTIVE test bed was modified to integrate the DES into the avionics suite with minimal cost and schedule impact (fig. 3).

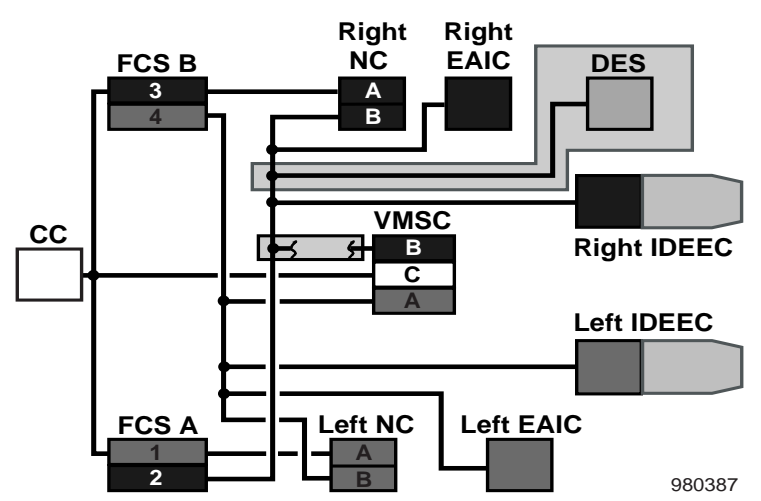

Figure 3. HISTEC Military Standard 1553 avionics bus modifications. 
The modification consisted of disconnecting Channel B of the VMSC from the aircraft MUX, and substituting the DES in its place. This swap allowed the IDEEC to communicate with the DES without incorporating any flight control computer (FCS) software changes. The latter advantage provided significant cost savings and minimized flight safety concerns.

\section{$\underline{\text { Instrumentation }}$}

The ACTIVE aircraft incorporates a flexible high-speed data acquisition system which transmits and records analog and digital parameters, and MIL-STD1553 data bus. A new pulse code modulation (PCM) system was added to the ACTIVE vehicle to accommodate the large amount of additional instrumentation required to support HISTEC. On the new PCM system, 7 temperature and 54 high-response pressure measurements were added to analog instrumentation. Over 3700 parameters were recorded onboard and simultaneously downlinked to the NASA Dryden mission control center during the HISTEC flights. Instrumentation included such categories of parameters as:

- Aircraft, engine, nozzle trims, commands, and effector feedbacks

- Engine, nozzle, fuel flow and quantity information

- Pilot activity and flight conditions

- Aircraft attitude and states

- Airdata including aircraft AOA, altitude, and Mach number

- Cockpit discretes and switches

- DES, IDEEC MUX traffic

- Inlet rake instrumentation including DES sensors

A description of the airdata system is worthwhile, considering its importance to the DES algorithm. The aircraft is equipped with an airdata computer to execute computations and furnish parameters required to aircraft systems and cockpit displays. The ADC receives inputs from a pitot-static system, AOA probes, and a total temperature probe. The ADC corrects these inputs for sensor error as required. The pitot-static system employs multiple pitot and static sources for redundancy, including left- and right-side of the forward fuselage and in each inlet duct. AOA probes are located on each side of the forward fuselage and measure local AOA. A single probe located on the left forward fuselage provides total temperature to the ADC. A standard flight research noseboom, separate from the ADC, provided another source of aircraft AOA and was the only measurement for AOSS.

Special consideration was given to the criticality of the instrumented inlet rake transducers. In past flight programs, pressure transducers have displayed sensitivity to the harsh operating temperature and vibration environment near engines. The severe environment where the HISTEC transducers were located posed a threat to their longevity. Because of their criticality to the success of the HISTEC experiment and the difficulty of replacing failed sensors, replacement criteria were defined and the sequence of testing was established to proceed from high transducer criticality, low risk flight conditions to low criticality, high risk flight conditions. As will be described later, the flight test was staged in two phases with the criticality for most of the inlet sensors relaxed during the second phase of flights. Additionally, supersonic testing, which provides the harshest transducer environment, was accomplished only after most of the subsonic testing was completed.

\section{$\underline{\text { Ground Tests }}$}

Verification and validation of the HISTEC system was required prior to flight for all hardware and software aircraft modifications. Avionics verification and validation ranged from unit level testing of software and hardware, to hardware-in-the-loop tests, to aircraft ground tests. Propulsion system validation testing included structural integrity tests for the instrumented inlet case, sea level functional tests, and an uninstalled engine run. Finally, integrated system validation testing was accomplished with all systems installed on the aircraft as it was to be configured for flight.

\section{$\underline{\text { Avionics Verification and Validation Tests }}$}

As part of the HISTEC preflight checkout, the software integration test (SIT) and hardware-in-theloop-simulation (HILS) tests were performed on the HISTEC avionics architecture. While these tests were not required for flight safety, they were required for software validation. The integration tests were conducted at the BPW facilities in St. Louis.

The FCS/DES/VMSC/IDEEC interfaces were verified in the SIT test. In this test, all the avionics boxes are integrated, just as they are in the aircraft. External inputs to the various boxes are emulated. Proper data bus communication can then be verified between the boxes. 
The proper operation of the AOA/AOSS prediction algorithm was verified in the HILS test. In this test, all the avionics units are connected, as in the SIT test, but the external inputs to the units are generated by a manned simulation of the aircraft. The HILS test allows the aircraft to be flown throughout the envelope with all avionics units functioning as they would on the aircraft. The need for the HILS test was verified, when the first entry found an error in the AOA/AOSS coding of the DES. The second entry verified proper operation of the algorithm. Had this error not been found in ground testing, it would have reduced the effectiveness of the flight test.

\section{Uninstalled Engine Run on M-37 Stand}

The objectives of the uninstalled engine run were to: (1) flight qualify the instrumented inlet case, (2) qualify the HISTEC sensors, electronics and software, and (3) define the steady and dynamic performance of the HISTEC instrumentation. These objectives were accomplished in approximately 11 hours of engine run time with five inlet screen configurations.

The HISTEC M-37 configuration, as shown in figure 4, consisted of the F100-PW-229 engine, engine mount, M-37 bell mouth, inlet ducts, and distortion screen mount. Test control, data recording, and control monitoring were performed in a nearby control room. Data recording equipment for the HISTEC instrumentation included three 16-channel recorders, each recording at 6000 samples per second for each channel. The control monitor could examine and record any internal control variables.
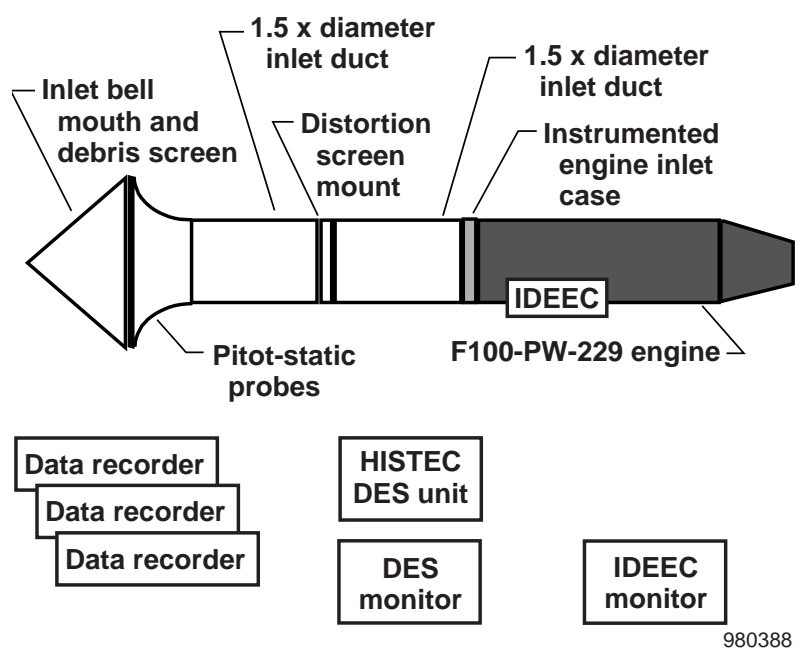

Figure 4. M-37 uninstalled testing configuration.
Inlet configurations included standard and complex screens to obtain undistorted flow patterns, as well as radial and circumferential distortion patterns. Also, the circumferential screen was rotated through three orientations in $120^{\circ}$ increments.

The objectives of the uninstalled test were successfully achieved. The inlet case and HISTEC system performed as expected. Instrumentation failures encountered during the uninstalled testing were predominantly wiring related. All failures were corrected prior to aircraft installation.

The most significant modification identified by uninstalled testing was the blending of the OD wall static pressure ports to the inlet case surface. These were originally designed to protrude into the flowpath about $0.250 \mathrm{in}$. , in an attempt to escape the separated region downstream of the aircraft inlet seal. At high flow rates the position error caused by this configuration was too large to be reliably corrected. After review, one of the ports was redesigned and installed to protrude just $0.080 \mathrm{in}$. The redesign was checked during the uninstalled testing and demonstrated successful solution to the problem. Subsequently, all ports were ground to 0.040 in. prior to aircraft installation.

\section{Integrated System Validation Tests}

Just prior to the first HISTEC flight, a series of five installed engine ground tests were performed as a final check of the integrated system as it was configured for flight. The purpose of ground testing was to demonstrate the test aircraft was airworthy and that the HISTEC system was ready for flight testing. After successfully completing these tests a functional check flight was accomplished to ensure all critical flight systems operated as expected and that aircraft handling qualities were acceptable.

\section{$\underline{\text { Instrumentation Ground Test }}$}

The first integrated systems tests measured the accuracy and response of all the HISTEC pressure and temperature transducers by applying known pressures and temperatures and comparing the readings. The instrumentation test also evaluated the accuracy of the DES sensor outputs on the MUX and the DES ID transducer averaging circuit. During the test, all aircraft systems were electrically powered, including the IDEEC, but the engines were not running. The test objectives were successfully met. All HISTEC transducers were accurate and working properly. The DES outputs on the MUX were nominal and the averaging circuit worked as expected. 


\section{Functional Ground Test}

A functional ground test was then accomplished to verify nominal aircraft systems and HISTEC specific systems. The functional ground test was conducted in the hangar with external electrical power, hydraulic power, and cooling air. Engine operation was not required during this test. The functional test objectives included verifying the proper operation of the following:

- flight control initiated-built-in-test,

- MUX communications,

- nominal operations of the VMSC, DES, IDEEC computers,

- HISTEC-specific cockpit switches and displays,

- proper engage and disengage states of the VMSC, DES, and IDEEC computers,

- system response to MUX and power failures,

- functionality of DES pressure transducers, and

- the ability to engage the HISTEC system during simulated flight conditions.

All of the functional ground test objectives were successfully met.

\section{Hangar Radiation Test}

The next step in the integrated systems tests, the hangar radiation test, involved verifying that aircraft telemetry was received and displayed in the control room and that the displays operated as expected. The test required external electrical power and external cooling air. In order to check out all of the displays it was necessary to have engines running. All test objectives were successfully met. HISTEC control room displays and operation were nominal.

\section{Electromagnetic Compatibility Test}

As a result of the modifications to aircraft electrical systems, a fourth integrated systems test was required, the electromagnetic compatibility (EMC) test. This test was completed with engines running. The EMC evaluation of the new HISTEC system with ACTIVE subsystems revealed no interference conditions.

\section{Combined Systems Test}

A combined systems test (CST), the final integrated systems test, was accomplished with the aircraft configured exactly as it would be for flight and all procedures were followed as if preparing for a flight.
The CST was conducted with engines on. Different engine power settings were tested to collect ground static distortion patterns. The aircraft was required to be tied down during the CST. The purpose of the CST was to find any discrepancies that the integrated systems tests may have failed to identify. The CST was successfully accomplished and initial inlet data gathered.

\section{Flight Tests}

The successful execution of a flight research program involves the careful integration and balancing of research objectives and safety considerations. Safety was always considered in the approach and design of the HISTEC system and its implementation into the ACTIVE vehicle. A flight test plan that included specific mission objectives was designed to accomplish the overall objectives, and mission planning was reviewed before each flight operation. Test technique development determined the most efficient means of gathering flight research data without sacrificing data quality or flight safety.

\section{$\underline{\text { Safety Considerations }}$}

In the design of the HISTEC flight test, system safety was emphasized in the interest of aircraft safety. System safety was addressed by assessing the risk involved, implementing safety design features, verifying and validating the system, performing a safety hazard analysis, and flight operational procedures. Some of the major steps taken to mitigate risks included: (1) not activating the ACTIVE vectoring nozzles during HISTEC tests, (2) installing the HISTEC system on only the right-hand engine while leaving the left-hand engine unmodified, and (3) not making any software or hardware changes to the aircraft flight control system. As a side note, this approach resulted in substantial benefits to costs and scheduling.

The HISTEC risk assessment relied on the history of similar programs flown on the F-15 HIDEC and ACTIVE. During the HIDEC program, F100-PW-1128 engines (of similar design to the F100-PW-229), were aggressively controlled to improve performance while reducing stability stall margins. ${ }^{8}$ HISTEC benefited from the safety features and the proven safe track record of the ACTIVE vehicle and flight test team. ACTIVE, as a research test bed, has proven the flexibility to accommodate diverse experiments-such as an adaptive performance optimizing control, an acoustics experiment, and vectoring nozzles-while retaining uncompromising safety. Because the aircraft is capable of safe operation with a single engine, the risk 
of any HISTEC-related failure causing injury or significant damage was greatly reduced.

The safety assessment of the HISTEC-instrumented inlet rake design was based upon structural analysis, ground testing, and flight test experience with inlet rakes of similar design. Flight clearance of the inlet case was gained from uninstalled engine ground tests. During flight tests, the inlet case was inspected after every flight as a further safety precaution. The reliability of the instrumentation was initially of some concern given the harsh environment. However, these concerns were put to rest as nearly all the instrumentation remained intact throughout the HISTEC flight testing.

The right engine IDEEC and DES required a safety review. The hardware for both the IDEEC and the DES had been previously flight qualified (as part of production programs) and this hardware is of sufficient reliability for operational aircraft, and thus by extension were acceptable for the ACTIVE aircraft. The software for both of these computers was checked during the SIT and HILS tests.

Several system safety design features were implemented for HISTEC. These included the engage-disengage logic, input signal management, trim command limiting, and engine stall protection. The engage-disengage procedures for HISTEC were borrowed from ACTIVE and were designed to prevent unintended trim application, to allow for engagement only by the pilot, and to allow the pilot to disengage the system at any time by several different means. Input signal management checked the validity of inputs before processing any trim commands and if engaged could cause the system to uncouple if any input failed. Trim command limiting by the HISTEC software included limits to allowable engine trims. For example, the software only allowed negative incremental trims to the engine pressure ratio, thereby increasing stability margins and decreasing the likelihood of an engine stall. The reliability of the HISTEC software was demonstrated in software integration tests and during portions of the integrated systems validation testing.

Well-established Dryden safety procedures were also followed during flight tests. An additional requirement for HISTEC was that all test points be flown on the NASA ACTIVE piloted simulation prior to flight on the aircraft. This simulation requirement also proved valuable in defining and practicing test techniques. The flight test approach involved a buildup in risk where initial testing was accomplished with the system disengaged and without trim application. Later, after reviewing test results and verifying algorithm operation, testing was accomplished with the system coupled.

Because the HISTEC was an incremental change to the ACTIVE aircraft, the starting point for the HISTEC hazard analysis was the baseline ACTIVE hazard analysis. The incremental hazard analysis for HISTEC revealed that all HISTEC-specific risks had been reduced to an acceptable level and that some of the ACTIVE risks relating to the vectoring system were not applicable.

\section{Test Plan Design and Approach}

Overall flight test objectives were to demonstrate a high stability engine control that could accurately estimate in-flight inlet distortion and its effects on stall margin loss, and to flight validate the SMC. A secondary objective was to augment the inlet distortion database. Flight testing involved two phases to accomplish the primary objectives. Specific Phase I objectives were as follows:

- Quantify inlet distortion at steady-state and transient flight conditions

- Correlate measured inlet distortion from total pressure measurements to DES pressure measurements

- Define any DES software changes that may be required for calibration and implement these before Phase 2

- Demonstrate acceptable DES accuracy at selected flight conditions.

Specific Phase II objectives were as follows:

- Demonstrate accurate inlet distortion estimation at steady-state and transient flight conditions

- Demonstrate functional engine trim capability to accommodate inlet distortion

- Demonstrate adequate AOA and AOSS prediction and resulting engine trims.

The first phase of flight test consisted of a baseline algorithm checkout and refinement along with inlet distortion database collection. No engine trims were applied during this phase. Algorithm updates were made after analyzing Phase 1 flight data. The second phase of testing was completed with the HISTEC system coupled, where DES-generated engine trims were applied when requested, during periods of relatively higher inlet distortion. Target conditions of AOA, AOSS, 
engine airflow, Mach number, and altitude were all required to be within specified tolerances.

The flight test points shown in Figure 5 were designed to evaluate HISTEC in both a research and an operational environment. Data were obtained during steady aerodynamic conditions. These conditions consisted of:

- Stabilized points at various altitudes and Mach numbers, including supersonic

- Combinations of constant AOA and AOSS limits.

The above aerodynamic conditions were held steady during fixed engine power levels and during engine transients.

Transient flight conditions included:

- AOA sweeps (two rates) to aircraft limits at various flight conditions and engine power settings

- AOSS sweeps to aircraft limits at various flight conditions and engine power settings

- Combinations of AOA and AOSS sweeps to aircraft limits
- Basic operational fighter maneuvers (offensive, defensive and neutral)

- NASA-supplied aircraft maneuvers (maximum-g windup turns, pushovers with sideslip)

\section{$\underline{\text { Test Technique Development }}$}

To achieve these target conditions, flight maneuver techniques were developed in the NASA ACTIVE piloted simulator, as mentioned in the "Safety Consideration" section. A range of maneuvers from the relatively benign maneuver of straight and level flight to the more aggressive Split-S maneuver to nearly $30^{\circ} \mathrm{AOA}$ were developed and flown. Maneuvers at steady aerodynamic conditions and rapid AOA and AOSS transients were accomplished at mostly subsonic Mach numbers. Because aircraft takeoffs provide the highest inlet distortion levels, data were also collected during takeoffs with the HISTEC system disengaged and then repeated with the system engaged.

\section{Control Room Monitoring}

Aircraft and HISTEC systems instrumentation was monitored from the DFRC Mission Control Center during flight test operations. Information was provided through a range of stripcharts and displays to ensure

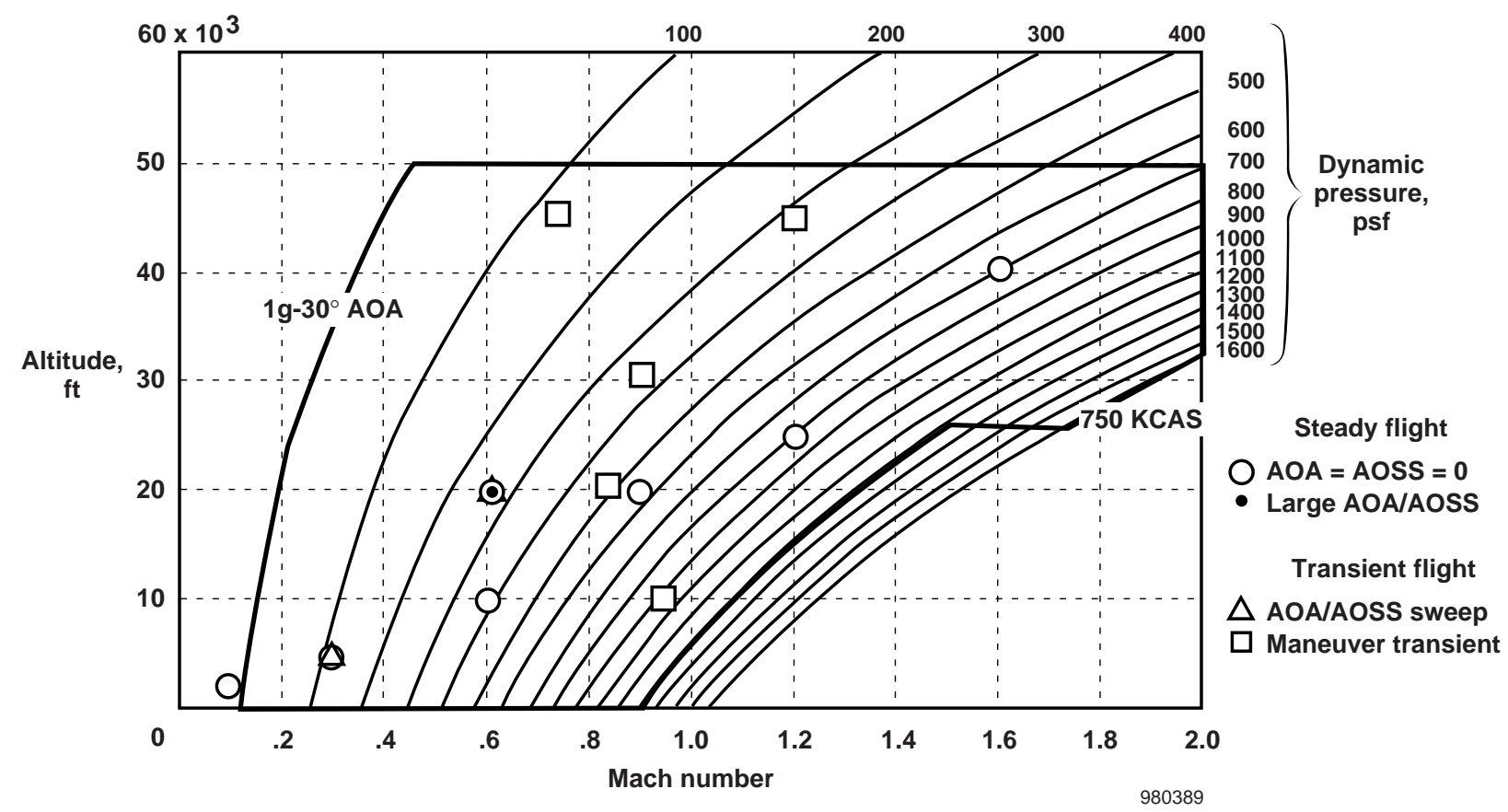

Figure 5. ACTIVE flight envelope overlaid with HISTEC test points. 
safe operation and mission success. Extensive displays of real-time data including inlet instrumentation, HISTEC IDEEC parameters, and parameters from the DES algorithm and computer status. These displays provided the rapid interpretation of critical measurements. The control room displays supplied research engineers with the critical information needed to make decisions concerning the flight test progression. This capability for near real-time decision making resulted in productivity increases and greater testing efficiency. For example, flight measured AOA was monitored and compared with the desired target AOA conditions to determine whether the test point was acceptable or needed repeating. The AOA data quality decision could be made within the same mission thus avoiding the possibility of having to wait for postflight data evaluation to determine whether or not the test needed repeating. Another example of how the control room displays and procedures benefited the flight tests was shown in the ability to display (1) the DES trims and (2) the fan and compressor stall margins in the SMC. This allowed a determination of whether or not the trims were being properly applied to the engine and whether or not repeat tests or software modifications would be required.

\section{Flight Operations}

Flight operations were typically conducted twice a day for up to 3 days a week. Preparation for a typical mission involved preflight aircraft checkout, including checkout of instrumentation systems and engine inlet case inspections. Inspections were necessary to verify that no structural damage had occurred to the inlet case and that the instrumentation was ready for flight. Prior to starting engines, and as part of the day-of-flight aircraft checks, the instrumentation systems were turned on to obtain inlet pressure readings at ambient conditions. Comparisons were made with the known ambient conditions to track any transducer drift between flights. Once in flight, but prior to acquiring the first test conditions, and again just prior to completion of the flight, a data repeatability test was flown at the standard conditions of Mach 0.6 at an altitude of 20,000 ft and maximum nonaugmented power setting during wings-level cruise. This repeatability test verified that no significant transducer drift had occurred during flight.

\section{$\underline{\text { Illustrative Results }}$}

To give an indication of the type of results that were obtained from the flight test program, a sample of typical results are presented here. For a more thorough review and discussion of flight data analysis, results and conclusions of the HISTEC sensors, algorithms, and control laws, see Southwick et al. in reference 8. The data for the following figures and discussion were obtained at Mach 0.6, at an altitude of 20,000 ft, and at an intermediate power setting.

\section{Inlet Distortion Measurement and Estimation}

Inlet face total pressure patterns were generated from the DES static pressure ports at the wall and compared with those patterns more directly measured from the 35 total pressure probes to qualitatively assess the accuracy of the inlet distortion estimation at steady and transient aerodynamic conditions. Figure 6 presents instantaneous total pressure contours taken from a data sample during an AOA sweep as viewed from the engine looking forward. In general, the contour patterns showed excellent agreement between the total pressure probes and DES static pressure ports. Circumferential distortion, as determined by the DES, matched very well with that measured with the total pressure probes. At this condition, the DES predicted only slightly higher radial distortion than was measured. Generally the steady-state distortion intensities derived from the wall static ports are within 2 percent of those computed from the total pressure probes. The dynamic distortion intensities are generally within 5 percent.

\section{$\underline{\text { Stability Management Distortion Accommodation }}$}

During aircraft maneuvering, when sufficient inlet distortion was sensed by the DES, fan-operating line trim commands in terms of fan pressure ratio were sent to the engine control and then applied by the IDEEC in terms of engine pressure ratio. Figure 7 shows aircraft and system response from a data sample during an AOA sweep at an altitude of 20,000 ft and Mach 0.6 for an intermediate power setting. In figure 7(a), the time history of AOA shows AOA rates generated during the maneuver reached about $4^{\circ}$ per sec on the pull-up and about minus $7^{\circ}$ per sec on the recovery. A maximum AOA of $27.5^{\circ}$ was reached. Engine pressure ratio, figure 7(b), tracks the AOA as expected, and is consistent for both increasing and decreasing AOA. The HISTEC-controlled engine is down-matched as the stability debit begins to exceed the available stability margin, and is removed when the debit decreases below the available margin. Fan pressure ratio trims from the DES cross-plotted with AOA in figure 8 show that the trims are nearly linear with AOA. 


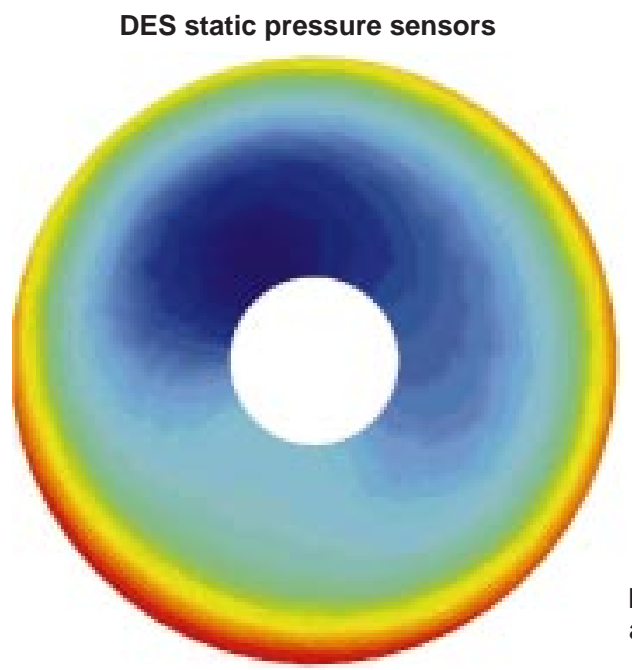

Right-hand engine aft looking forward

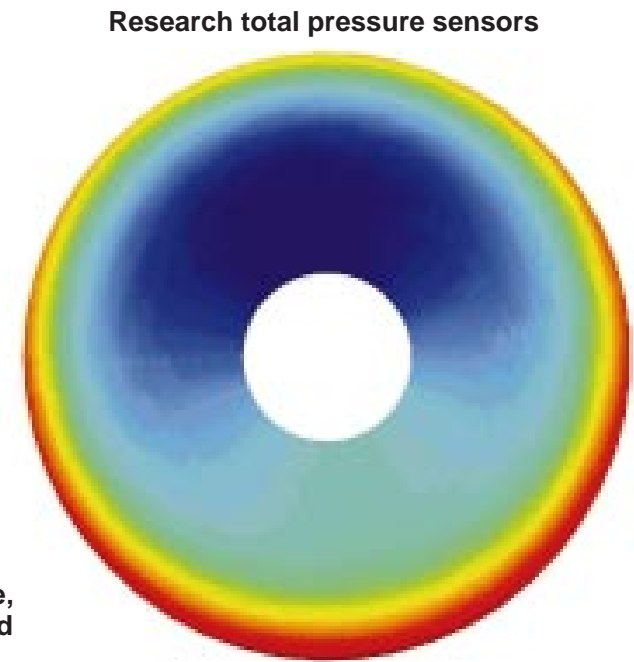

Normalized total pressure

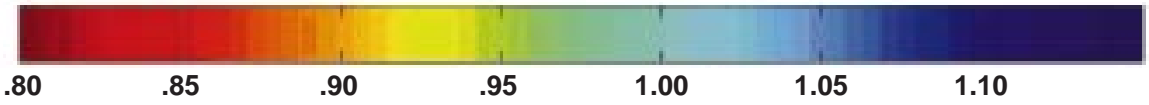

980390

Figure 6. Comparison of DES-derived contours to measured contours of total pressure at the inlet face for Mach 0.6 at an altitude of $20,000 \mathrm{ft}$ and $21^{\circ} \mathrm{AOA}$ and $0^{\circ} \mathrm{AOSS}$.

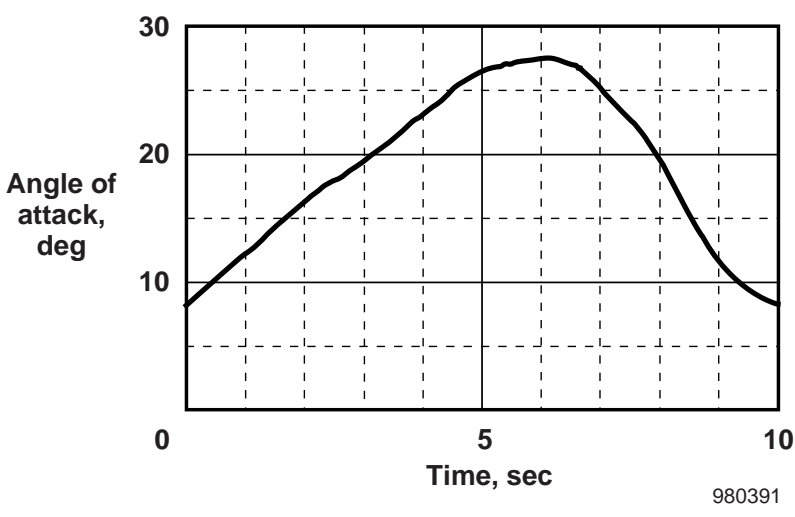

(a) Angle of attack time history.

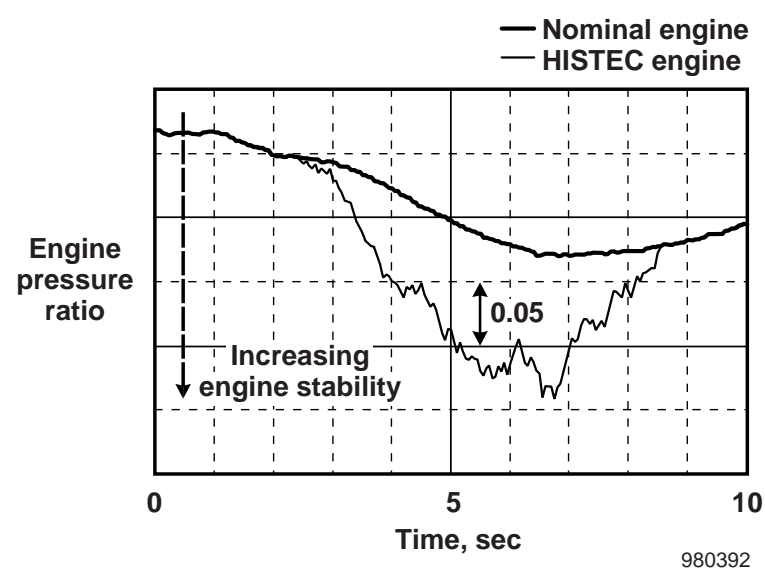

(b) Engine pressure ratio time history.

Figure 7. Flight test results, maneuver distortion accommodation. 


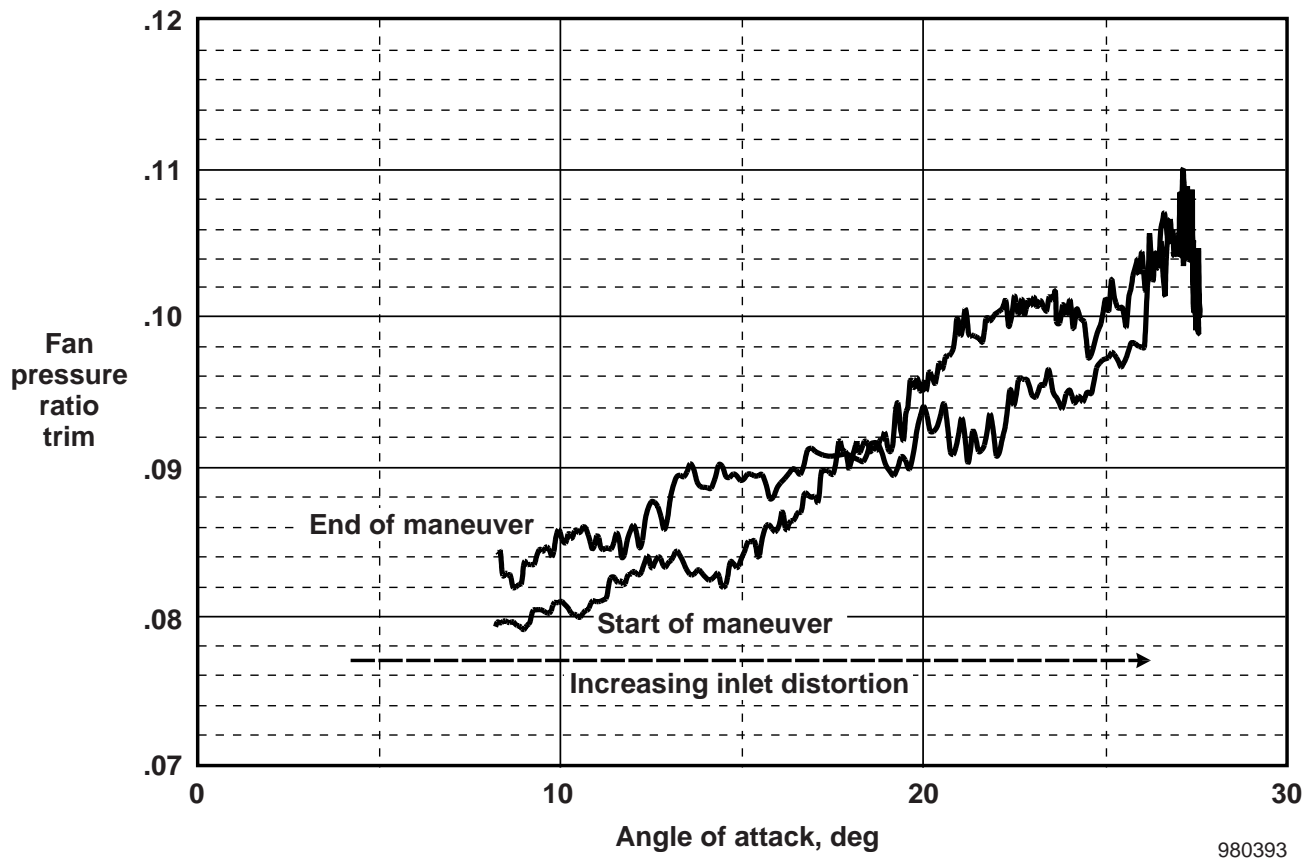

Figure 8. Fan pressure ratio trim as compared with angle of attack.

\section{Concluding Remarks}

The HISTEC distortion-tolerant control has been successfully demonstrated in flight on the F-15 ACTIVE aircraft. All flight test objectives were successfully met over the course of 10 flights and over 100 test points. Approximately 65 gigabytes of high quality inlet distortion and DES algorithm data were collected. A maximum angle of attack of $29^{\circ}$ and angle of sideslip of $5^{\circ}$ were achieved, yielding increased levels of distortion. A maximum Mach number of 1.6 was attained. During the first phase of flight test, it was verified that inlet distortion was accurately estimated by the DES in flight. Only minor algorithm updates were required between flight missions. During the second phase of testing, engine stability accommodation was demonstrated when the stability management control applied stabilityenhancing trims during periods of high distortion levels. Because of the preparation and up front test planning, execution of the flight tests was extremely efficient and safe.

\section{$\underline{\text { References }}$}

${ }^{1}$ Stewart, James F., Frank W. Burcham, and Donald H. Gatlin, Flight-Determined Benefits of Integrated Flight-Propulsion Control Systems, NASA TM-4393, June 1992.

\footnotetext{
${ }^{2}$ Highly Integrated Digital Electronic Engine Control Symposium, NASA CP-3024, February 1989.
}

${ }^{3}$ Southwick, Robert D., George W. Gallops, Louis J. Larkin, and Kurt J. Sobanski, High Stability Engine Control (HISTEC) Phase I: Algorithm Development, vol. I, Final Report and Appendix A, NASA CR-198399, Sept. 1995.

${ }^{4}$ DeLaat, J., R. Southwick, G. Gallops, and J. Orme, The High Stability Engine Control (HISTEC) Program: Flight Demonstration Phase, AIAA-98-3756, July 1998.

${ }^{5}$ Southwick, R., G. Gallops, J. DeLaat, and J. Orme, High Stability Engine Control (HISTEC) Flight Test Results, AIAA 98-3757, July 1998.

${ }^{6}$ Smolka, James W., Laurence A. Wallace, Major Gregory H. Johnson, Gerard S. Schkolnik, Curtis W. Burger, Timothy R. Conners, John S. Orme, Karla S. Shy, and C. Brent Wood, F-15 ACTIVE Flight Research Program, 1996 Report to the Aerospace Profession, 40th Symposium Proceedings, The Society of Experimental Test Pilots, Sept. 1996, pp. 112-145.

${ }^{7}$ Doane, P., R. Bursey, and G. Schkolnik, F-15 ACTIVE: A Flexible Propulsion Integration Testbed, AIAA 94-3360, June 1994.

${ }^{8}$ An Electronic Workshop on the Performance Seeking Control and Propulsion Controlled Aircraft Results of the F-15 Highly Integrated Digital Electronic Control Flight Research Program, Proceedings of the Electronic Workshop, compiled by Sheryll Goecke Powers, NASA TM-104278, Jan. 1995. 
Public reporting burden for this collection of information is estimated to average 1 hour per response, including the time for reviewing instructions, searching existing data sources, gathering and maintaining the data needed, and completing and reviewing the collection of information. Send comments regarding this burden estimate or any other aspect of this collection of information, including suggestions for reducing this burden, to Washington Headquarters Services, Directorate for Information Operations and Reports, 1215 Jefferson Davis Highway, Suite 1204, Arlington, VA 22202-4302, and to the Office of Management and Budget, Paperwork Reduction Project (0704-0188), Washington, DC 20503.

1. AGENCY USE ONLY (Leave blank)

2. REPORT DATE July 1998

\section{REPORT TYPE AND DATES COVERED}

Technical Memorandum

4. TITLE AND SUBTITLE

Development and Testing of a High Stability Engine Control (HISTEC)

System

6. AUTHOR(S)

WU 529-20-04-00-33-00-MGT

John S. Orme, John C. DeLaat, Robert D. Southwick, George W. Gallops, and Paul M. Doane

7. PERFORMING ORGANIZATION NAME(S) AND ADDRESS(ES)

NASA Dryden Flight Research Center

P.O. Box 273

Edwards, California 93523-0273

5. FUNDING NUMBERS

9. SPONSORING/MONITORING AGENCY NAME(S) AND ADDRESS(ES)

10. SPONSORING/MONITORING

AGENCY REPORT NUMBER

National Aeronautics and Space Administration

Washington, DC 20546-0001

NASA/TM-1998-206562

11. SUPPLEMENTARY NOTES

Presented at the 34th AIAA/ASME/SAE/ASEE Joint Propulsion Conference, Cleveland, Ohio, July 13-15, 1998. John Orme, NASA Dryden, Edwards, California; John DeLaat, NASA Lewis Research Center, Cleveland, Ohio; Robert Southwick and George Gallops, United Technologies Corporation, Pratt \& Whitney, West Palm Beach, Florida; Paul Doane, Boeing Phantom Works, St. Louis, Missouri.

\begin{tabular}{|l|l|}
\hline 12a. DISTRIBUTION/AVAILABILITY STATEMENT & 12b. DISTRIBUTION CODE
\end{tabular}

Unclassified-Unlimited

Subject Category 05, 07

13. ABSTRACT (Maximum 200 words)

Flight tests were recently completed to demonstrate an inlet-distortion-tolerant engine control system. These flight tests were part of NASA's High Stability Engine Control (HISTEC) program. The objective of the HISTEC program was to design, develop, and flight demonstrate an advanced integrated engine control system that uses measurement-based, real-time estimates of inlet airflow distortion to enhance engine stability. With improved stability and tolerance of inlet airflow distortion, future engine designs may benefit from a reduction in design stall-margin requirements and enhanced reliability, with a corresponding increase in performance and decrease in fuel consumption. This paper describes the HISTEC methodology, presents an aircraft test bed description (including HISTEC-specific modifications) and verification and validation ground tests. Additionally, flight test safety considerations, test plan and technique design and approach, and flight operations are addressed. Some illustrative results are presented to demonstrate the type of analysis and results produced from the flight test program.

14. SUBJECT TERMS

Air data, Avionics, Controls, Engine control, Engine stability, F-15 ACTIVE, Flight research, Inlet distortion, Propulsion

\begin{tabular}{|l|l|}
\hline 17. SECURITY CLASSIFICATION & 18. SECURITY CLASSIFICATION \\
OF REPORT & OF THIS PAGE \\
Unclassified & Unclassified \\
\hline
\end{tabular}

15. NUMBER OF PAGES

19

16. PRICE CODE

A03

20. LIMITATION OF ABSTRACT

Unlimited 